\title{
First evaluation of an absolute quantum gravimeter (AQG\#B01) for future field experiments
}

\author{
Anne-Karin Cooke, Cédric Champollion, and Nicolas Le Moigne \\ Géosciences Montpellier, Univ. Montpellier, CNRS, Univ. des Antilles, Montpellier, France \\ Correspondence: Anne-Karin Cooke (annekacooke@gmail.com)
}

Received: 1 August 2020 - Discussion started: 21 August 2020

Revised: 16 January 2021 - Accepted: 21 January 2021 - Published: 24 March 2021

\begin{abstract}
Quantum gravimeters are a promising new development allowing for continuous absolute gravity monitoring while remaining user-friendly and transportable. In this study, we present experiments carried out to assess the capacity of the AQG\#B01 in view of future deployment as a field gravimeter for hydrogeophysical applications. The AQG\#B01 is the field version follow-up of the AQG\#A01 portable absolute quantum gravimeter developed by the French quantum sensor company Muquans. We assess the instrument's performance in terms of stability (absence of instrumental drift) and sensitivity in relation to other gravimeters. No significant instrumental drift was observed over several weeks of measurement. We discuss the observations concerning the accuracy of the AQG\#B01 in comparison with a state-of-the-art absolute gravimeter (Micro-gLaCoste, FG5\#228). We report the repeatability to be better than $50 \mathrm{~nm} \mathrm{~s}^{-2}$. This study furthermore investigates whether changes in instrument tilt and external temperature and a combination of both, which are likely to occur during field campaigns, influence the measurement of gravitational attraction. We repeatedly tested external temperatures between 20 and $30^{\circ} \mathrm{C}$ and did not find any significant effect. As an example of a geophysical signal, a $100 \mathrm{~nm} \mathrm{~s}^{-2}$ gravity change is detected with the AQG\#B01 after a rainfall event at the Larzac geodetic observatory (southern France). The data agreed with the gravity changes measured with a superconducting relative gravimeter (GWR, iGrav\#002) and the expected gravity change simulated as an infinite Bouguer slab approximation. We report 2 weeks of stable operation under semi-terrain conditions in a garage without temperaturecontrol. We close with operational recommendations for potential users and discuss specific possible future field applications. While not claiming completeness, we nevertheless
\end{abstract}

present the first characterization of a quantum gravimeter carried out by future users. Selected criteria for the assessment of its suitability in field applications have been investigated and are complemented with a discussion of further necessary experiments.

\section{Introduction}

Gravimetry studies the spatial and temporal variations in the Earth's gravity field which can be linked to changes in mass distribution studied in various disciplines of the Earth sciences. Applications include geodesy and large-scale geodynamics such as tectonics and slow subsidence (Camp et al., 2011; Hwang et al., 2010) as well as crust deformation and glacial isostatic uplift (Mazzotti et al., 2011; Olsson et al., 2019). Gravimetry has furthermore proved to be a tool in natural hazard assessment such as a monitoring of volcanic activity (Bonvalot et al., 1998; Carbone et al., 2017) or mapping of underground voids or the study of earthquakes (Imanishi, 2004). Applications in energy and resources comprise geothermal fields (Pearson-Grant et al., 2018), $\mathrm{CO}_{2}$ storage reservoirs (Sugihara et al., 2017), or artificial groundwater recharge facilities (Kennedy et al., 2016). Gravimetric methods furthermore find application in the context of oil and mineral exploration and prospecting (e.g. Ferguson et al., 2007; Hinze et al., 2013). In hydrology gravity measurement provide possibilities to monitor storage dynamics of local and landscape-scale groundwater resources (e.g. Creutzfeldt et al., 2008, 2010; Jacob et al., 2010; Hector et al., 2014, 2015; Fores et al., 2016a; Güntner et al., 2017) and even evapotranspiration rates (Van Camp et al., 2016). Applications and active gravity research fields have been ex- 
tensively reviewed by Crossley et al. (2013) and Van Camp et al. (2017).

Gravimeters are devices that measure the gravitational attraction $g$ on the Earth's surface. Nowadays gravimeters based on different measurement principles exist for various applications. Gravimeters can be characterized by their measurement performance: the repeatability of a measurement refers to the agreement between repeated measurements and is usually assessed by carrying out several repeated location changes in between measurements. The sensitivity (or precision) of a gravimeter is a relative uncertainty and refers to the smallest change in gravitational acceleration that the gravimeter is able to detect. We refer to stability as the absence of a significant instrumental drift in time or correlated noise. The accuracy of a gravity measurement describes to which extent it can be considered as correct in absolute terms and refers to the uncertainty of a measurement relative to an absolute standard (Niebauer, 2015).

Relative gravimeters sense the gravitational attraction indirectly by measuring the force needed to counteract gravitation by stabilizing a test mass and are used to monitor relative gravity changes. These devices show drifts that can become important within days (spring gravimeters) or months (superconducting gravimeters; Van Camp et al., 2017). Relative gravimeters require regular calibration with absolute gravimeters as reference stations and repeated looped or absolute measurements to eliminate drifts in field surveys (Hector and Hinderer, 2016; Kennedy and Ferré, 2015) and can be sensitive to temperature changes (for example with a relative spring gravimeter as in Fores et al., 2016b). The most sensitive relative gravimeters are superconducting gravimeters and achieve a high precision of about $0.1 \mathrm{~nm} \mathrm{~s}^{-2}$ while measuring continuously at a sampling rate of $1 \mathrm{~Hz}$. They are based on magnetic levitation instead of a mechanical spring (Hinderer et al., 2015).

Absolute gravimeters estimate the norm of the gravitational acceleration $g$ during vertical free fall in vacuum (Niebauer et al., 1995). Absolute gravimeters are mostly based on a free-fall corner-cube retro-reflector in a vacuum chamber with an instrumental uncertainty in the order of a few tens of $\mathrm{nm} \mathrm{s}^{-2}$ (Niebauer, 2015). Currently available absolute gravimeters are not suitable for continuous monitoring due to mechanical parts with a limited lifespan. This limits the number of free-fall experiments and requires frequent instrument repairs. Their operation usually requires a high technical skill level and they cannot be operated by a nonspecialist.

Quantum sensing offers new possibilities for measuring inertia and the development of quantum absolute gravimeters. The general measurement principle of an absolute quantum gravimeter (AQG) is that of matter-wave interferometry (Peters et al., 2001; Merlet et al., 2010). The atoms can be exploited as test masses as well as a tool to measure the travelled path in order to sense gravity (Peters et al., 2001). A laboratory realization, the cold-atom gravimeter (CAG) de- veloped at LNE-SYRTE in the context of the Kibble balance, has demonstrated unprecedented performances both in sensitivity and accuracy. It has since participated in International Comparisons of Absolute Gravimeters (ICAGs) showing a better short-term sensitivity than absolute gravimeters and a well-quantified accuracy budget (Jiang et al., 2012; Francis et al., 2013; Gillot et al., 2014). Numerous research institutions and private companies work on different realizations of cold-atom gravimeters (Geiger et al., 2020) such as GAIN (Germany; Hauth et al., 2013) or WAG-H5-1 (China; Huang et al., 2019).

Robust atom manipulation, as a crucial step towards the realization of a field instrument, was achieved by atom trapping and detection without the necessity to align several optical components. This has been realized thanks to a single hollow pyramidal reflector, allowing operation with a single optical beam, and leading to a compact implementation (after Bodart et al., 2010). An exhaustive review on the state of the art of cold-atom gravity-inertial sensors, different sensor types, applications, and differences in performance has been provided by Geiger et al. (2020). The first commercially available gravimeter (AQG\#A) based on this technology has been developed by https://www.muquans.com/ (last access: 1 July 2020). The compact design enabled a mobile instrument that does not require special training in operation. Advances in on-the-fly correction of external effects have contributed to a compact and stable instrument of high sensitivity measuring at a $2 \mathrm{~Hz}$ sampling rate. A stability better than $10 \mathrm{~nm} \mathrm{~s}^{-2}$ during 1 month of operation was observed, and the instrument's repeatability was preliminary quantified to be in the same order of magnitude (Ménoret et al., 2018) for $24 \mathrm{~h}$ of averaging.

The main aims of this study are to assess the stability and repeatability of the first field absolute quantum gravimeter (Muquans, AQG\#B01) in view of future deployment as a field gravimeter for hydrogeophysical applications. The assessment is done during continuous measurements and experiments (impact of orientation or transportation) in comparison to absolute and relative gravimeters. The sensitivity to tilt and temperature changes as well as the interaction between both are of crucial importance to assess the suitability of the AQG\#B01 as a field instrument. Its sensitivity to ambient temperature changes is evaluated by conducting tests in a controlled environment. Finally, recommendations are presented for the future use of the AQG\#B01 in field experiments.

\section{Site and instrumental set-up}

The field site allows for the monitoring of gravity with complementary instruments and of environmental variables to link gravity variations to mass changes occurring in the surroundings of the study site. Instrument tests and monitoring from December 2019 to April 2020 were car- 
ried out at the Larzac observatory, which is part of the French National Research Infrastructure OZCAR (Gaillardet et al., 2018, OZCAR-RI H+ Larzac - France: https://deims. org/83b01fa5-747f-47be-9185-408d73a90fb2, last access: 1 July 2020) and the European long-term environmental monitoring network ELTER (Mollenhauer et al., 2018). The Larzac observatory is located on the La Jasse site in L'hospitalet-du-Larzac in southern France. The observatory is highly instrumented with hydro-meteorological monitoring (eddy co-variance flux tower, rain gauges) and well suited for hydrogeophysical studies (Fores et al., 2018). It is also part of the French seismological and geodetic network RESIF (https://www.resif.fr, last access: 1 July 2020; Volcke et al., 2014). The Larzac site further serves as a site for gravimeter testing, for instance in a study on the AQG\#A01 or gPhoneX (Micro-g LaCoste; Fores et al., 2019). A superconducting gravimeter on the site (GWR, iGrav\#002) has been monitoring gravity variations for almost a decade. Residual gravity changes caused by hydrological mass changes of less than $100 \mathrm{~nm} \mathrm{~s}^{-2}$ have been identified (Fores et al., 2016a). An absolute free-fall gravimeter (Micro-g-LaCoste, FG5\#228) has been transported to and operated at the site. During the International Key Comparison of Absolute Gravimeters in 2017 (CCM.G-K2.2017), the FG5\#228 showed a degree of equivalence of $3 \mathrm{~nm} \mathrm{~s}^{-2}$ with the 12 other absolute gravimeters and $55 \mathrm{~nm} \mathrm{~s}^{-2}$ uncertainty within $95 \%$ confidence (Wu et al., 2020). In this study, the FG5\#228 serves as a reference. In the Larzac observatory, the AQG\#B01 and FG5\#228 were operated on the same concrete pillar with approximately $1 \mathrm{~m}$ distance between both instruments.

The AQG\#B01 is the field version follow-on of the AQG\#A01 described in Ménoret et al. (2018). It is based on the same measurement specifications and overall architecture but underwent a complete system redesign in order to meet outdoor operation requirements and to increase the stability of the measurement. The laser module and sensor head have been provided with an active thermal stabilization, allowing for a potential operation temperature range between 0 and $40^{\circ} \mathrm{C}$. Power consumption has been reduced to $250 \mathrm{~W}$. Battery operation is possible but has not been tested yet. This study focuses on operation relying on external power supply. Improvement in ease of use and transportability has been achieved with each element weighing $40 \mathrm{~kg}$ or less. The sensor head, the laser system, and the control unit each come with a dedicated transport box that can be carried by two people. A fourth transport box is provided for the tripod, cables, connectors, and the laptop. The enclosure for the lasers and the sensor head has been made water- and airtight. Connectors and cables are suitable for field conditions, and a reduction in the number of connectors further facilitates fast and efficient field set-up. As an example, shifting the AQG\#B01 in the Larzac observatory from one measurement location to another takes around $5 \mathrm{~min}$ for one person. The AQG GUI software allows for measurement control, data storage, and processing on a connected laptop. Calibrations prior to measurement start can be launched manually or automatically. Data quality control is provided by the software, and recalibration is initiated if predefined thresholds are undershot (e.g. number of atoms).

In late April 2020, additional AQG\#B01 and FG5\#228 measurements and tests were continued in the facilities of the laboratory Géosciences Montpellier in the cellar, about $100 \mathrm{~km}$ southwest of the Larzac site. The laboratory is in an urban area on the Montpellier University campus. Previous FG5\#228 measurements show small gravity changes (less than $50 \mathrm{~nm} \mathrm{~s}^{-2}$ over 1 year; Jacob et al., 2008) for a closeby site on campus. Environmental noise is monitored with a large band seismometer. Due to the Covid-19 lockdown, the environmental noise is largely reduced: less difference in noise level is seen between workdays, weekends, and public holidays.

On 2 June 2020 the AQG-B01 was transported from the Géosciences laboratory to a private garage in a residential area in Montpellier (in approximately $3 \mathrm{~km}$ distance to Géosciences).

\section{Methods and experiments}

The experiment timeline and data availability are displayed in Fig. 2. The iGrav\#002 data are available continuously. Software malfunctioning or updates and seismic events caused data gaps in the AQG\#B01 series. In late January a seismic event made a restart necessary and caused no damage to the instrument. Improvements to avoid loss of measurements caused by these incidents are in progress. An instrument test was conducted remotely by the developer on 23 March. Apart from those, an offset of $100 \mathrm{~nm} \mathrm{~s}^{-2}$ was observed to emerge in the AQG\#B01 gravity time series before the second temperature test on 10 February 2020. The cause is still under investigation and the authors are in contact with the instrument developer. Additional monitoring variables registered during operation are being investigated. Up to this point, the main hypothesis is mechanical stress in the sensor head, acquired in between temperature tests.

\subsection{Drift, accuracy, and sensitivity}

The sensitivity is assessed by calculating the Allan deviation (Allan, 1966) of the gravity residual signal. The Allan deviation is calculated for the three gravimeters (FG5\#228, AQG\#B01, and iGrav\#002) after classical post-processing: calibration and drift correction of the iGrav\#002 data set, correction for solid Earth and ocean loading tides using Tsoft (Camp and Vauterin, 2005), and atmospheric pressure and polar motion for all data sets. Polar coordinates were obtained from the International Earth rotation and Reference systems Service (https://hpiers.obspm.fr/eop-pc/index. php, last access: 4 June 2020). Site-specific combined ocean 


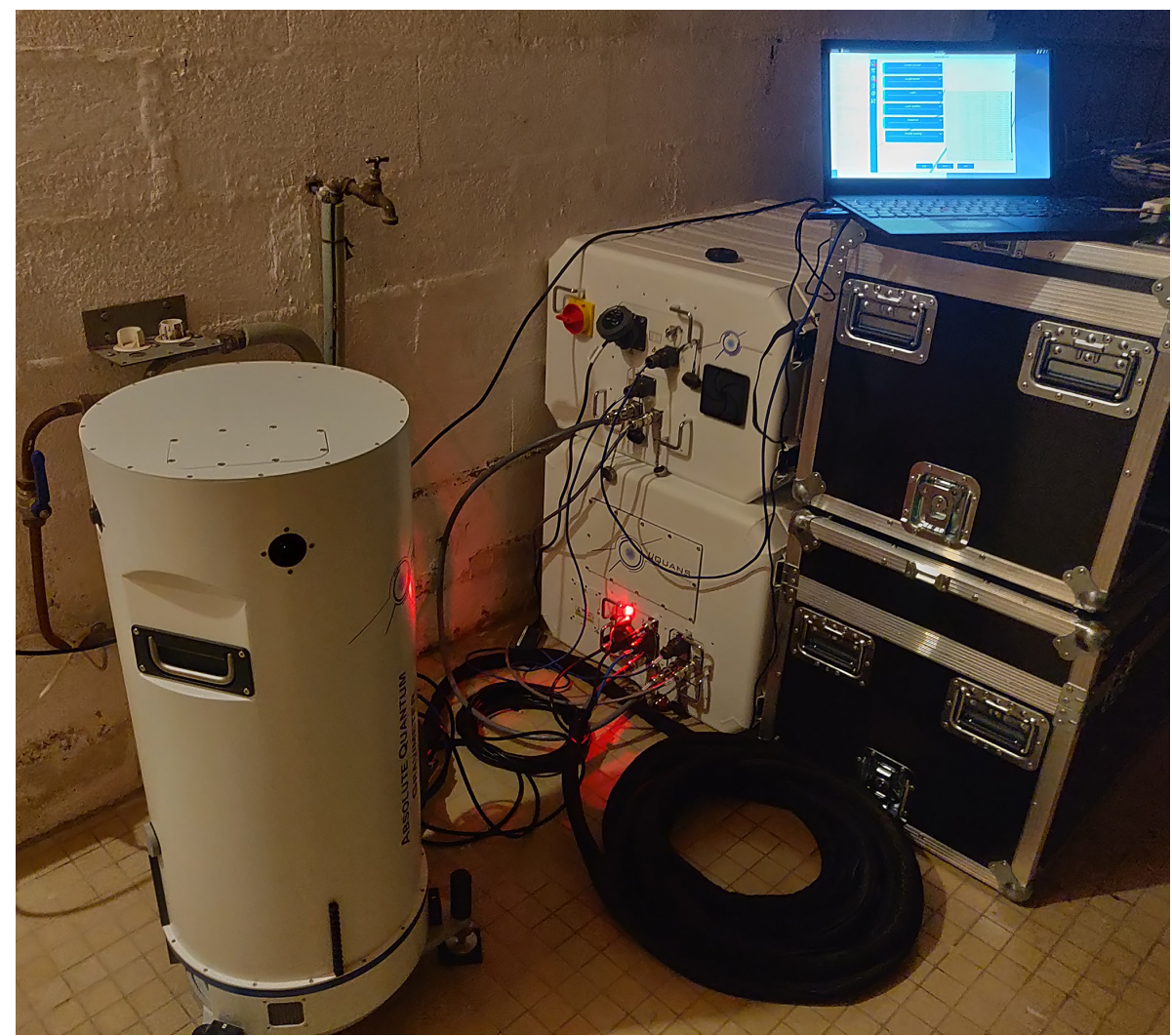

Figure 1. AQG-B01 in a garage in Montpellier in June 2020. The sensor head (left) is connected with the laser and electronic systems by $5 \mathrm{~m}$ of cables. The AQG GUI software is used on a laptop to control the measurement as well as to correct, visualize, and analyse the gravity data.

and solid Earth tidal parameters had been estimated with the ETERNA (Wenzel, 1996) software based on long-term iGrav\#002 time series (Fores et al., 2016a). Gravity residuals refer hereafter to the processed gravity data set. For the AQG\#B01, the corrections mentioned are carried out using the AQG GUI software.

The influence of global, non-local hydrological, and atmospheric gravity effects on the Larzac site was estimated using the EOST loading service (http://loading.u-strasbg.fr, last access: 4 June 2020; Boy and Hinderer, 2006; Boy and Lyard, 2008; Boy et al., 2009) applying the model GLDAS/Noah (v2.1; Rodell et al., 2004). Gravity residuals obtained from AQG\#B01 and iGrav\#002 were related to local cumulative precipitation obtained from on-site rain gauges to assess the detectability of small hydrogeological mass changes. A 1D hydrological model using rainfall as input describes the gravity changes due to hydrological mass changes adequately (Fores et al., 2016a); hence to display the gravity changes caused by rainfall an infinite homogeneous Bouguer anomaly was assumed. The Bouguer plate was calculated according to

$\delta g_{\mathrm{B}}=2 \pi \rho G H$.

$G$ refers to the gravitational constant and $\rho$ to the density of water, and the plate thickness $H$ refers to the cumula- tive rainfall. The Bouguer plate equivalent was corrected for the estimated averaged daily deep percolation discharge of $1 \mathrm{~mm} \mathrm{~d}^{-1}$ (Fores et al., 2018). The investigated precipitation event took place during the winter months; evapotranspiration was thus not considered. The FG5\#228 measurements provide absolute reference points to assess any drift with time in the AQG\#B01 time series. The period between the 28 November 2019 and 25 January 2020 was used for drift assessment, as numerous tests (tilt, temperature) were conducted afterwards. Daily averaged residuals are compared in order to assess the accuracy of the AQG\#B01.

The difference of effective measurement height requires a correction for the vertical gravity gradient when the accuracy of the AQG\#B01 is estimated. For this set-up, the AQG\#B01 effective measurement height was at 65.1; that of the FG5\#228 was at $121.77 \mathrm{~cm}$. The vertical gravity gradient required to correct for the vertical gravity differences between the FG5\#228 and AQG\#B01 measurement locations in Larzac and Montpellier has been estimated with a relative Scintrex CG5 and CG6 gravimeter. The vertical gravity gradients were estimated from measurements on two heights of $1.2 \mathrm{~m}$ vertical difference. Estimated vertical gravity gradients at the Montpellier site were found to be approximately $-2.9 \mathrm{kE}\left(1 \mathrm{kE}=10 \mathrm{~nm} \mathrm{~s}^{-2} \mathrm{~cm}^{-1}\right)$. In the Larzac observa- 


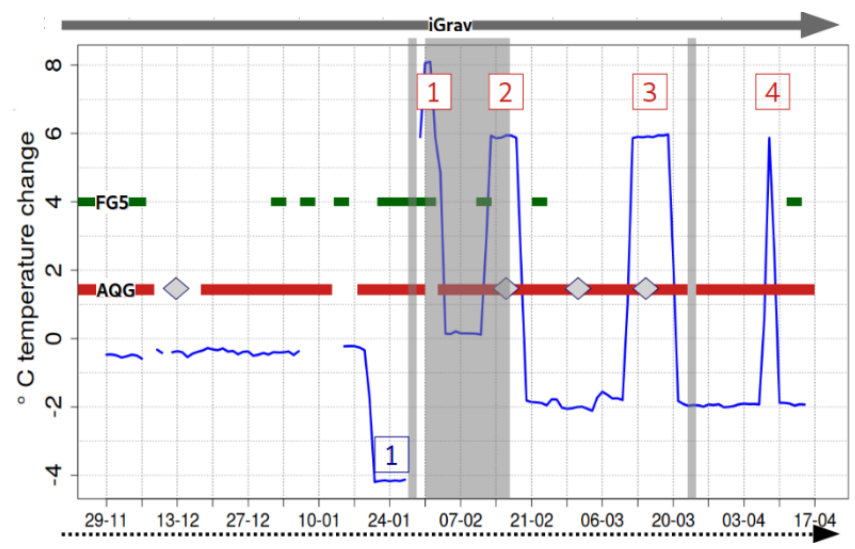

Figure 2. Timeline and data availability for the campaigns at Larzac observatory December 2019-April 2020. The AQG-B01 data series are marked in red; the FG5-228 measurements are marked in dark green. The iGrav-002 measured continuously (marked in dark grey). AQG-B01 data at dates marked in grey in later January, early February, and late March were not considered in the analysis, due to inconsistencies during the experiments, as explained in Sect. 4.4.2. The thin blue line represents the residuals from the mean observatory temperature to illustrate the temperature tests. One test has been carried out at reduced temperatures and four at increased temperatures. Grey diamonds during the AQG-B01 series mark the dates of tilt tests carried out on the AQG-B01.

tory the estimated vertical gravity gradient on measurement point p1 (FG5) is $-3.226 \mathrm{kE}$ with a standard deviation of 0.022 and $-3.220 \mathrm{kE}$ with a standard deviation of $0.017 \mathrm{kE}$ for measurement point $\mathrm{p} 2$ (AQG), averaged over 1 year of monthly measurements (Cooke et al., 2021). AQG\#B01 and FG5\#228 gravity residuals were thus transferred to the same height by correcting for a vertical gravity gradient of -3.22 and $-3.225 \mathrm{kE}$ in the Larzac observatory and for -2.86 and $-2.89 \mathrm{kE}$ in the laboratory in Montpellier, respectively.

\subsection{Adjustment of ambient temperature in the observatory}

The observatory is kept at relatively stable $24^{\circ} \mathrm{C}$ in the weeks before and in between the experiments. The AQG\#B01 was operated during five periods of modified ambient temperature with periods of standard temperature in between (Fig. 2). The temperature in the observatory was changed by adjusting the air conditioning device. The first temperature test comprised a reduced temperature, followed by four tests of higher temperatures, relative to the $24^{\circ} \mathrm{C}$ default temperature listed in Table 1. During the first period of increased temperature, an elevated noise level and interruption due to the seismic event were observed by both the iGrav\#002 and the AQG\#B01, and these periods were therefore not considered in the analysis.
Table 1. Temperature test periods in the Larzac observatory.

\begin{tabular}{lllr}
\hline No. Start date & End date & $\begin{array}{r}\text { Temperature } \\
{ }^{\circ} \mathrm{C}\end{array}$ \\
\hline \multicolumn{2}{l}{ Cooling } \\
\hline \multicolumn{1}{l}{ 1 } & & \\
\hline \multicolumn{2}{l}{ Heating Jan 2020 } & 28 Jan 2020 & 20 \\
\hline 1 & 28 Jan 2020 & 3 Feb 2020 & 30 \\
2 & 12 Feb 2020 & 19 Feb 2020 & 30 \\
3 & 11 Mar 2020 & 21 Mar 2020 & 30 \\
4 & 7 Apr 2020 & 9 Apr 2020 & 30 \\
\hline
\end{tabular}

\subsection{Tilt calibration under adjusted ambient temperatures}

Instrument tilt variations are monitored by a tiltmeter located at the top of the sensor head. This allows for a constant monitoring and in-line post-correction of $g$ values according to the effective tilt experienced by the instrument. Mechanical alignment between the vertical measurement axis and the tiltmeter reference is susceptible to drifts. Uncorrected tilts lead to the measurement of a projection of $g$ as compared to a well-aligned, vertical measurement. The tiltmeter reference offset can be assessed using gravity measurements and directly used for gravity correction in the AQG acquisition software. For this calibration, several measurements $(\sim 20)$ are performed for various $x$ and $y$ tilt values, up to $1 \mathrm{mrad}$ from the initial position. The instrument's tilts in $x$ and $y$ are adjusted manually to reach a certain angle $\theta$, and the raw gravity data are then adjusted along a function of $\frac{1}{\cos \left(\theta-\theta_{0}\right)}$, in order to evaluate $\theta_{0}$, corresponding to the real vertical axis. The offset coefficient has been tested in the Muquans facilities in Talence (France) and has since been redone twice at the Larzac observatory. Furthermore, it was investigated whether the obtained offset coefficient had changed over time or had shown any response to temperature changes. The offset calibration test on 19 February 2020 was carried out in the Larzac observatory at an increased temperature of $28^{\circ} \mathrm{C}$ and 5 March 2020 at $22^{\circ} \mathrm{C}$.

\subsection{Manual tilt deregulation under adjusted ambient temperatures}

Temperature changes or temperature gradients may influence mechanical parts and tilt the instrument. To investigate possible interactions between temperature and tilt and to ensure reliable application of their corrections, manual tilt deregulation was carried out during phases of modified ambient temperature. Between 9 and 13 December 2019, manual tilt deregulation in $x$ and $y$ during room temperature was tested. On 11 March the room temperature was modified from 22 to $30^{\circ} \mathrm{C}$, and on the same day, the tilt in $x$ direction was manually set to $0.5 \mathrm{mrad}$. 


\subsection{Operation under semi-terrain conditions}

As an intermediate step between controlled observatory conditions and open-air measurements, the influence of diurnal temperature changes and anthropogenic noise was assessed by operating the AQG\#B01 in a garage in a residential area in Montpellier from 2 to 17 June 2020. The garage is connected to a house inhabited by three people. Initially, the garage doors were kept closed. The garage is not air-conditioned. To allow for a larger amplitude of diurnal temperature change, the doors were opened in the late evening and early morning starting from 8 June 2020.

During the last days of operation, several acquisition stops occurred that required a manual measurement relaunch and caused data gaps mainly during the night. The experience obtained from the operation in the garage shows that frequent measurement stops required software improvements and modifications in the response to instrumental variables in order to create a robust, continuous measurement system without the necessity of regular human intervention. These software updates have meanwhile been implemented.

\subsection{Repeatability}

On 17 April 2020 the AQG\#B01 was transported to the facilities of the laboratory Géosciences Montpellier on University campus and operated in the basement of the building. The distance between the Larzac observatory and Montpellier is about $100 \mathrm{~km}$ and there is $640 \mathrm{~m}$ difference in altitude. The transport to Montpellier was the second displacement of the AQG\#B01 after its first delivery to the Larzac observatory in November 2019. This implies the turn-off, disconnection, displacement, and cold restart of the instrument. The data were compared to FG5\#228 measurements at both sites. Small-scale repeatability was assessed using repeated gravity measurements on the same position in the gravity lab in the basement of Géosciences Montpellier. In between these measurements, the instrument was not turned off or disassembled, and only the measurement was temporarily stopped and the sensor head was moved within the room. Small-scale repeatability was therefore assessed under warm conditions without a full restart of the system. Vertical gravity gradients were additionally estimated with a relative gravimeter (Scintrex CG6).

\subsection{Coriolis effect}

Gravimeters are sensitive to a Coriolis shift, the Sagnac effect caused by the Earth's rotation. This effect can generate an additional bias in quantum interferometers. The horizontal atomic velocity component generates an additional Coriolis acceleration depending on the $\mathrm{E}-\mathrm{W}$ direction. This leads to a possible gravity bias (Peters et al., 2001; LouchetChauvet et al., 2011). By symmetrical construction (hollow pyramidal reflector and location of the detection photo- diodes), horizontal atomic velocities are reduced and the AQG\#B01 should only show a negligible sensitivity to the Coriolis effect as in the CAG gravimeter (Louchet-Chauvet et al., 2011). We assess the potential residual Coriolis effect in the AQG\#B01. By rotating the device by $180^{\circ}$, two opposite orientations are obtained; hence a change in sign of the Coriolis acceleration is expected. As in Louchet-Chauvet et al. (2011), the tests were carried out under the assumption that parameters do not change between the measurements. The same set-up was thus kept constant to rule out other systematic effects. Coriolis AQG\#B01 measurements last at least $24 \mathrm{~h}$ to reduce the effect of residuals after tidal correction.

\section{Results and discussion}

\subsection{Sensitivity}

The sensitivity of the AQG\#B01 is firstly evaluated by statistical time series analysis in comparison with other gravimeters and secondly by direct monitoring of natural gravity changes. It was calculated for the first week of December 2019 using $10 \mathrm{~min}$ AQG\#B01 data and $1 \mathrm{~min}$ iGrav\#002 data (Fig. 3). The first week in December 2019 shows no rainfall and no instrument tests were performed. At an integration interval of $1 \mathrm{~h}$, the sensitivity of the AQG\#B01 reached $10 \mathrm{~nm} \mathrm{~s}^{-2}$, the iGrav\#002 shows a higher sensitivity at short timescale, but both the iGrav\#002 and the AQG\#B01 reach the same level of sensitivity at $24 \mathrm{~h}$. All three instruments show a slight increase over a long time likely due to environmental noise and tide residuals.

The analysis of the Allan deviation showed that for averaging periods of a few hours the iGrav\#002 is the more sensitive instrument for this data set. The AQG\#B01 and the iGrav\#002 converge to show similar sensitivity of clearly better than $10 \mathrm{~nm} \mathrm{~s}^{-2}$ over a $24 \mathrm{~h}$ averaging period. For shorter integration intervals the sensitivities of the FG5\#228 and AQG\#B01 are comparable and lower than that of the iGrav. The AQG\#B01 does not achieve the sensitivity of laboratory quantum gravimeters that have achieved $2 \mathrm{~nm} \mathrm{~s}^{-2}$ in less than 2000 s (CAG; Gillot et al., 2014) or a mobile quantum gravimeter for which $0.5 \mathrm{~nm} \mathrm{~s}^{-2}$ after $1 \mathrm{~d}$ have been reported (GAIN; Freier et al., 2016).

For measurements longer than $1 \mathrm{~d}$, the AQG\#B01 is likely to be equally sensitive to the iGrav\#002. To obtain values closer to the possible highest sensitivity, a prolonged measurement of several weeks during a low-noise period of stable weather conditions and little human interventions is required, as it would be possible for example during summer months in the Larzac observatory. The Allan deviation of the AQG\#B01 data recorded in Montpellier showed a sensitivity of approximately $20 \mathrm{~nm} \mathrm{~s}^{-2}$ after $1 \mathrm{~h}$; after $24 \mathrm{~h}$ it was below $10 \mathrm{~nm} \mathrm{~s}^{-2}$. This decrease in sensitivity for the urban site compared to the Larzac observatory can be explained by the 


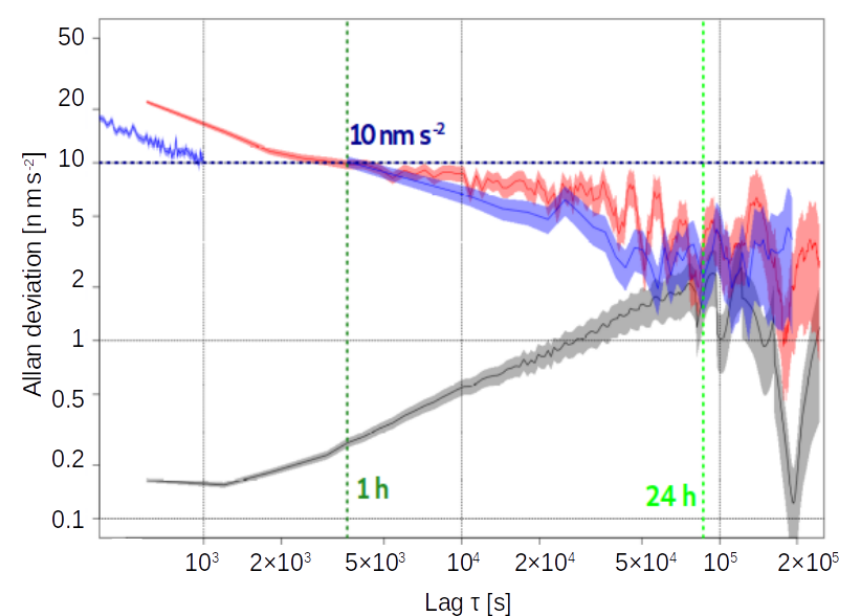

Figure 3. Allan deviation in $\mathrm{nm} \mathrm{s}^{-2}$ for the first week of December 2019 at the Larzac site. One-minute series were used for the iGrav-002 (grey), and $10 \mathrm{~min}$ data for the AQB-01 (red). The irregular sampling frequency of the FG5-228 (100 drops every $10 \mathrm{~s}$, then $2600 \mathrm{~s}$ break) was taken into account by plotting the shortterm Allan deviation ( $<1000 \mathrm{~s}$ for $10 \mathrm{~s}$ data) and the long-term $(1 \mathrm{~h}$ data) one separately (both blue). The horizontal blue dashed line shows the sensitivity benchmark of $10 \mathrm{~nm} \mathrm{~s}^{-2}$, the dark green vertical dashed line signifies the integration period of $1 \mathrm{~h}$, and the light green one that of $24 \mathrm{~h}$.

higher level of environmental noise in the university building.

A sensitivity of $10 \mathrm{~nm} \mathrm{~s}^{-2}$ is achieved in $1 \mathrm{~h}$ in a naturally low-noise environment and a sensitivity of $20 \mathrm{~nm} \mathrm{~s}^{-2}$ in an urban environment. In the context of characterizing the AQG\#B's sensitivity, the use of rubber pads below the tripod feet to reduce the effect of ground vibrations was assessed for future field experiments. Figure 4 shows that the Allan deviation is reduced for measurements of less than an hour. At $1 \mathrm{~h}$ duration, there is no significant difference, for longer integration times there is likely no major improvement. This needs to be reassessed for longer series and at periods of higher environmental noise as the activity at the university was reduced during the Covid-19 lockdown.

\subsection{Sensitivity to hydrogeological gravity changes}

A significant increase in $g$ of $\sim 80 \mathrm{~nm} \mathrm{~s}^{-2}$ between 13 and 27 December 2020 has been detected by the three gravimeters. As can be seen on Fig. 5a, the daily gravity residuals of all of them show high resemblance in their temporal variations and differ within their error margins.

Figure 5b shows the series of rainfall events in 2019. All three gravimeter signals follow the increase in gravity caused by the rise in soil water content in the aftermath of the rainfall events. The gravity time series continues to increase even after rainfall stops. This is expected since the infiltrating water moves further into the gravimeter's spatial sensitivity which

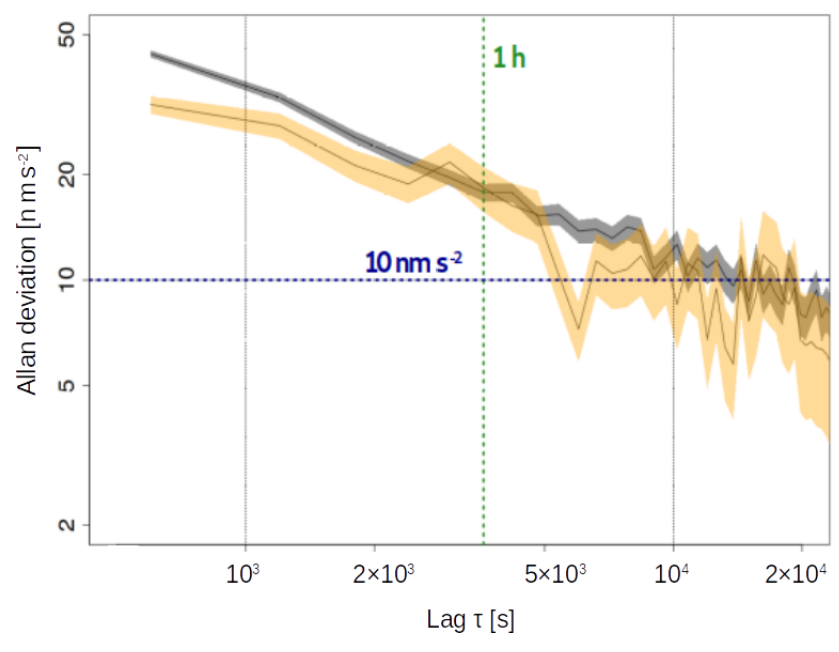

Figure 4. Comparison of sensitivity with (orange) and without (grey) placing the AQG-B01 tripod on rubber pads. The measurement without rubber pads were conducted on 23-26 April 2020 and those without pads on 28 April 2020.

can be described as two flat cones above and below with the instrument in the centre.

The measured change in $g$ is comparable to the expected increase caused by the corresponding Bouguer plate equivalent of the rainfall event. Figure $5 \mathrm{c}$ shows the Bouguer plate equivalent in $\mathrm{nm} \mathrm{s}^{-2}$ adjusted for deep discharge. Differences between the gravimeters' responses to the rainfall event can partly be explained by their position within the observatory building and the heterogeneity of rock properties. Local gravity measurements are impacted by the building due to shielding from precipitation, commonly referred to as the "umbrella effect" (e.g. Creutzfeldt et al., 2008; Deville et al., 2012; Hector et al., 2014; Fores et al., 2016a; Reich et al., 2019). The AQG\#B01 is operated on measurement point $\mathrm{p} 2$ in one corner of the building and hence more exposed to the area outside the building. The umbrella effect admittance can be calculated for sensor height and the specific measurement location within the building (Deville et al., 2012; Fores et al., 2016a).

An umbrella effect of the Larzac observatory, e.g. of $80 \%$ difference in the gravity of a given Bouguer plate measured on the central pillar (iGrav) inside the building, has been observed by Fores et al. (2016a) and decreases once the infiltration front moves further in. For the given Bouguer plate equivalent of 80 , up to $64 \mathrm{~nm} \mathrm{~s}^{-2}$ difference in $g$ can be expected for the iGrav. For the AQG\#B01 pillar an umbrella admittance of $46 \%$ has been estimated from a truncated Bouguer plate. Umbrella-effect-related differences between AQG\#B01 and iGrav\#002 could hence be up to several tens of $\mathrm{nm} \mathrm{s}^{-2}$. As the umbrella effect depends on the initial conditions and the previous rainfall events, it is difficult to determine the sign of the relative offset between the AQG\#B01, FG5\#228, and iGrav\#002 series without further information. 

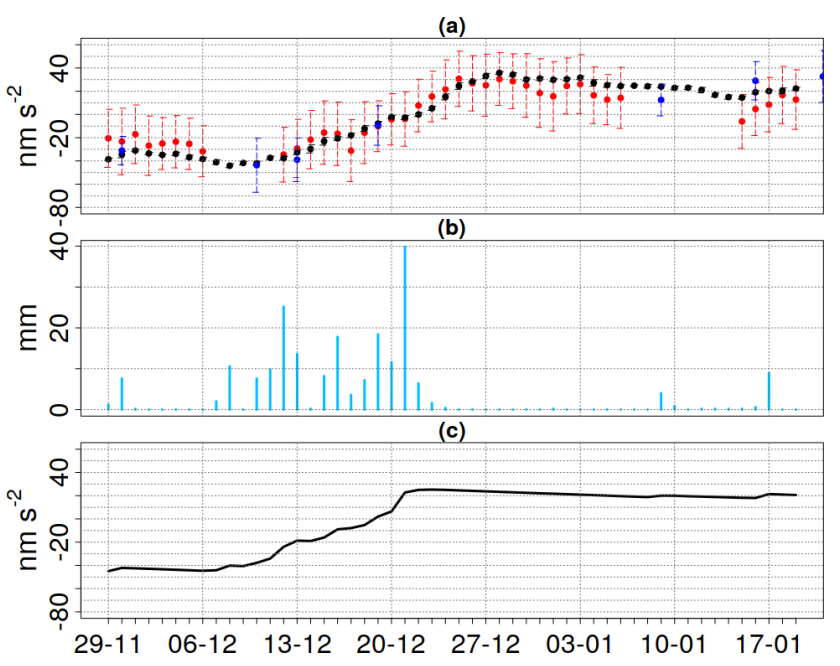

Figure 5. (a) AQG-B01 (red), FG5-228 (blue), and iGrav-002 (black) daily gravity residuals at the Larzac observatory in $\mathrm{nm} \mathrm{s}^{-2}$. Residuals of $g$ refer to the mean of the shown measurements. The error bars refer to the standard deviation of $24 \mathrm{~h}$ of measurement. (b) Rainfall series December 2019-January 2020 on the Larzac observatory, La Jasse site, L'hospitalet-du-Larzac. (c) Bouguer plate equivalent (in $\mathrm{nm} \mathrm{s}^{-2}$ ) of precipitation corrected for deep discharge.

To summarize, the AQG\#B01 clearly measures the gravity increase of less than $100 \mathrm{~nm} \mathrm{~s}^{-2}$ after the rainfall event in the same range as the iGrav. The gravity changes are coherent with previous studies at the site. The differences between the iGrav\#002 and AQG\#B01 data can be explained by limits of the sensitivity of the AQG\#B01 and the heterogeneity of the hydrogeological context in a karst area.

\subsection{Accuracy, repeatability, and drift}

The differences between the AQG\#B01 and the FG5\#228 during 2 months yielded an estimated, statistically insignificant drift of $-0.02 \pm 0.04 \mathrm{~nm} \mathrm{~s}^{-2} \mathrm{~d}^{-1}$. A longer measurement is currently in progress to investigate a potential long-term drift. Establishing the complete accuracy budget is a complex task for a new instrument and remains work in progress. A first approximate estimation of the accuracy is done by comparing the AQG measurements with the ballistic gravimeter (FG5\#228) in the Larzac observatory. Daily AQG\#B01 and FG5\#228 gravity residuals show high resemblance in their temporal variations and differ within their error margins (Fig. 5). The difference between AQG\#B01 and FG5\#228 based on 13 measurements (daily averages) between December 2019 and April 2020 in the Larzac observatory is on average $110 \mathrm{~nm} \mathrm{~s}^{-2}$ with a standard deviation of $31 \mathrm{~nm} \mathrm{~s}^{-2}$, with the FG5\#228 values being smaller than those measured with the AQG\#B01. For the Montpellier laboratory, the difference between both instruments is based on $24 \mathrm{~h}$ averages of 10 AQG\#B01 measurements between 27 April and 14 May 2020 and one FG5\#228 measurement on 10 June 2020. The
Table 2. AQG-B01: small-scale repeatability in Montpellier in 2020. Differences as residuals from the mean of the listed measurements, based on $24 \mathrm{~h}$ averages. The standard deviation refers to $24 \mathrm{~h}$.

\begin{tabular}{lrr}
\hline Date & $\Delta g\left[\mathrm{~nm} \mathrm{~s}^{-2}\right]$ & $\mathrm{SD}\left[\mathrm{nm} \mathrm{s}^{-2}\right]$ \\
\hline 27 Apr 2020 & -43 & 46 \\
28 Apr 2020 & -5 & 36 \\
3 May 2020 & 19 & 41 \\
8 May 2020 & -8 & 110 \\
13 May 2020 & 27 & 66 \\
27 May 2020 & -9 & 60 \\
\hline
\end{tabular}

difference showed $44 \mathrm{~nm} \mathrm{~s}^{-2}$ with a standard deviation of $66 \mathrm{~nm} \mathrm{~s}^{-2}$, with the FG5\#228 values being higher than those of the AQG\#B01.

Absolute comparison between both instruments is limited due to the set-up on different locations on the pillars and is impacted by the uncertainty related to the vertical gravity gradient (VGG) correction. An offset in vertical gravity gradient correction between FG5\#228 and AQG\#B01 of $10 \mathrm{E}\left(\mathrm{s}^{-2}\right)$ for the difference in height between the two instruments' sensors $\left(\delta_{\text {height }}=56.67 \mathrm{~cm}\right)$ accounts for an uncertainty of $5.7 \mathrm{~nm} \mathrm{~s}^{-2}$. The VGG for the pillars in the observatory can be estimated by repeated relative gravimeter measurements on different heights, and their uncertainty has been estimated to be around $20 \mathrm{E}$ (Cooke et al., 2021). Hence, about $11 \mathrm{~nm} \mathrm{~s}^{-2}$ of uncertainty is due to the fact that the VGG cannot be estimated more precisely up to this point. The possibility of a more precise estimation of the VGG employing AQG measurements on tripods is being discussed and in preparation. Likely due to soil moisture changes, VGG at the Larzac site may vary by several tens of $\mathrm{E}$ over weeks and months (Cooke et al., 2021). We recommend taking the accuracy assessment at the Larzac site with caution and repeating the measurements together with the FG5 in the near future.

Small-scale repeatability tests were only carried out in Montpellier. Table 2 shows an average small-scale repeatability of $3 \mathrm{~nm} \mathrm{~s}^{-2}$ with a standard deviation of $25 \mathrm{~nm} \mathrm{~s}^{-2}$ for repeated measurements on the same point and orientation after returning from displacements and other experiments.

AQG\#B01 was operated on two measurement points within the same room in the Géosciences laboratory at about $1 \mathrm{~m}$ distance, of which one serves FG5\#228 measurements. At this short distance, no considerable horizontal difference in $g$ is expected. CG6 relative gravity measurements were carried out with two instruments (CG6\#120 and CG6\#125) on 26 March 2020 on both points and found a negligible difference in $g$ of $2 \pm 6 \mathrm{~nm} \mathrm{~s}^{-2}$. The difference in $g$ measured with the AQG\#B01 between point 1 and point 2 is $15 \pm 48 \mathrm{~nm} \mathrm{~s}^{-2}$. The measurement on point 2 was carried out using rubber pads under the tripod. The rubber pads had no significant effect in the $10 \mathrm{~min}$ averaged gravity readings. 
Only a small decrease in the gravity readings dispersion at short timescale $(<10 \mathrm{~min})$ was observed.

To summarize, these first results show a repeatability of $3 \mathrm{~nm} \mathrm{~s}^{-2}$ with a standard deviation of $25 \mathrm{~nm} \mathrm{~s}^{-2}$ and no detectable drift over 2 months' operation. No impact of transport and displacement such as mechanical relaxation on the gravimeter was observed for small $(1 \mathrm{~m})$ or large $(100 \mathrm{~km}$ by car) distances. The complete accuracy budget is still under investigation. Additional location changes between the sites with both the AQG\#B01 and the FG5\#228 are required to reliably quantify the repeatability. Due to the potential error margin caused by the uncertainty mentioned earlier and introduced by the differences in vertical gravity gradient correction and measurements on different pillars, the accuracy in relation to the FG5\#228 cannot be estimated completely up to this point.

\subsection{Temperature and tilt}

\subsubsection{Tiltmeter calibration}

The stability of the tiltmeter offset is important both for long-term monitoring and for the repeatability of the measurements after transport by car. Tilts of $5 \mu \mathrm{rad}$ probably lie within measurement uncertainty. A tilt bias of $50 \mu \mathrm{rad}$ leads to an error of $12.3 \mathrm{~nm} \mathrm{~s}^{-2}$ and at small angles increases in a quadratic way which leads to $49 \mathrm{~nm} \mathrm{~s}^{-2}$ for $100 \mu \mathrm{rad}$. The tiltmeter offset calibration changed by 4.7 for $x$ and by $3.8 \mu \mathrm{rad}$ for $y$ between Talence and the Larzac observatory ( $\sim 400 \mathrm{~km})$, which is within measurement uncertainty. The tilt calibration obtained from data acquired in the Larzac observatory at $30^{\circ} \mathrm{C}$ on 19 February 2020 yields very similar results to the calibrations carried out on 31 October 2019 in Talence at $20^{\circ} \mathrm{C}$. On 5 March 2020 a partial test of certain chosen tilts at $22^{\circ} \mathrm{C}$ was carried out that showed coherent results to the test carried out at $30^{\circ} \mathrm{C}$ on 19 February 2020 . The tiltmeter offset calibration carried out in Talence and in Larzac lie almost 4 months apart and include the transport of the instrument from Talence to the Larzac site. The obtained offset values hence showed very minor changes over time, after transport, or at different external temperatures. The data showed that the tilt calibration is likely to be independent of temperature and to stay stable over time.

\subsubsection{Influence of temperature}

During the temperature experiment AQG\#B01 residuals did not show any statistically significant correlation with external temperature. Gravity residuals, external temperature, and tilts are displayed in Fig. 6. The AQG\#B01 showed no significant shift in the range of 20 to $30^{\circ} \mathrm{C}$ nor during episodes of tilt change. The visible variations lie within the earlier observed variations and uncertainty range. Relative offsets between AQG\#B01 and iGrav\#002 can be linked to the umbrella effect and karst heterogeneity as discussed in
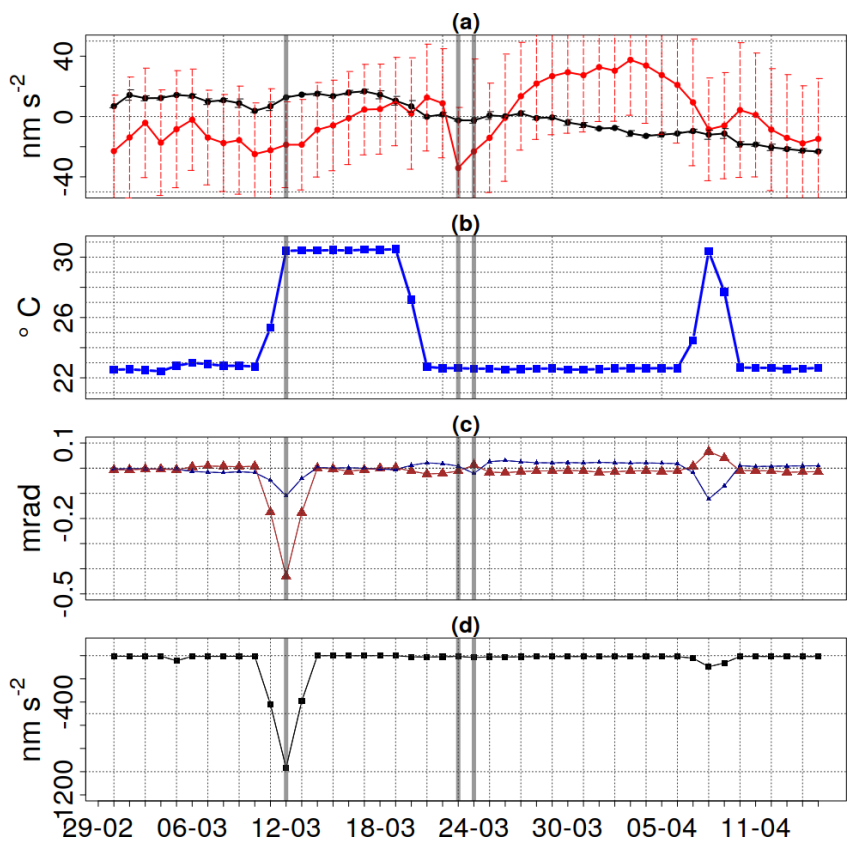

Figure 6. (a) Residuals of $g$ for the iGrav-002 (black) and AQGB01(red). (b) External temperature (blue). (c) Tilts in $x$ (brown) and $y$ (dark blue) for the tests 3 and 4 in March and April 2020 (see Fig. 1 for the timeline). (d) Tilt correction combined for $x$ and $y$ in $\mathrm{nm} \mathrm{s}^{-2}$. Dates marked as grey were subject to further instrument tests and adjustments.

Sect. 4.2. Precipitation was negligible during these measurements, and thus no significant effect of precipitation was observed in the iGrav\#002 monitoring. Temperature's impact on the AQG\#B01 gravity residuals was difficult to assess considering the first two episodes of elevated temperatures. Experimental conditions varied between the tests, and the results were not conclusive. Possibly due to the malfunctioning of the air conditioning, three spikes in temperature occurred during the first test. On 31 January, 1 February, and on 3 February 2020 approximately $35^{\circ} \mathrm{C}$ were reached for about $8 \mathrm{~h}$ each time, before decreasing again to settle at $30^{\circ} \mathrm{C}$. During the second temperature test an insulating cover around the sensor head had not been removed resulting in an increase in temperature in the sensor head above nominal operation conditions. The sensor head can be easily wrapped in the fitting insulation (down) cover.

AQG\#B01 and iGrav\#002 residuals differ by less than $50 \mathrm{~nm} \mathrm{~s}^{-2}$. The reduced temperature test $\left(20^{\circ} \mathrm{C} ; 20-28 \mathrm{Jan}-\right.$ uary) did not cause any significant gravity response to increased external temperatures. In March and April, the tilts stay stable before, during, and after the temperature test, and no remarkable shift between the residuals of $g$ obtained with the AQG\#B01 compared to those obtained with the iGrav\#002 is observed (Fig. 6). 


\subsubsection{Combined tilt and temperature tests}

Manually adjusted tilts during temperature changes did not show a visible change in $g$ recorded by the AQG\#B01. As can be seen in Fig. 6, the tilts showed a minor response during the last temperature test in early April. No impact on the corrected $g$ value (with a tilt correction of $\sim 1000 \mathrm{~nm} \mathrm{~s}^{-2}$ ) is observed. Tilts return to values close to zero after a change in temperature.

Simultaneous manual tilt deregulation and room temperature change did not lead to any clear shift of the difference in $g$ between the value of the AQG and that of the iGrav. This result suggests that the measurement of $g$ is not impacted by temperature. It cannot be ruled out that tilts of more than $1 \mathrm{mrad}$ require a different correction than small tilts. It is thus recommended to keep the sensor head well levelled during operation. The gravity series obtained with the AQG\#B01 before, during, and after an elevated temperature of $30^{\circ} \mathrm{C}$ in March and April 2020 show no impact of these. To reproduce these findings, further temperature experiments and larger ranges should be carried out, potentially exploring also much lower temperatures.

\subsubsection{Operation under semi-terrain condition}

Daily averages of $g$ show a standard deviation of less than $50 \mathrm{~nm} \mathrm{~s}^{-2}$, and differences between daily averages during the 2 weeks of operation lie within statistical uncertainty (Fig. 7a). Temperatures in the garage vary between 20 and $30^{\circ} \mathrm{C}$. Strong and fast temperature drops were the result of opened garage doors. As can be seen in Fig. 7c, during periods of external temperature a change in sensor head tilts occurs. Tilts returned to values close to zero within hours. Maximal inclinations of about $0.15 \mathrm{mrad}$ were found for tilts in the $x$ direction. Tilts in the $y$ direction stayed more stable and show generally fewer variations. After a manual recalibration of the tilt after 11 June 2020, tilts move in opposite directions than before, which is likely related to a change in equilibrium after each re-calibration. The residents entered the garage several times throughout the day from the interior door. The opening of the outward garage doors for a temperature change caused increased air circulation in the room. Possible impacts of these winds on tripod levelling and an imbalance in temperature of different sides of the tripod cannot be ruled out and need to be investigated. We did not explicitly measure wind or humidity changes. However, opening the doors clearly caused noticeable air circulation in the room. During those 2 weeks, both dry and sunny as well as very rainy weather conditions were observed without significant variations in the measured gravity by the AQG.

As expected, the sensitivity (Fig. 8) is reduced compared to the Larzac site. Overall, $26 \mathrm{~nm} \mathrm{~s}^{-2}$ are reached after $1 \mathrm{~h}$ of averaging, sensitivity is better than $10 \mathrm{~nm} \mathrm{~s}^{-2}$ after $24 \mathrm{~h}$ of averaging.

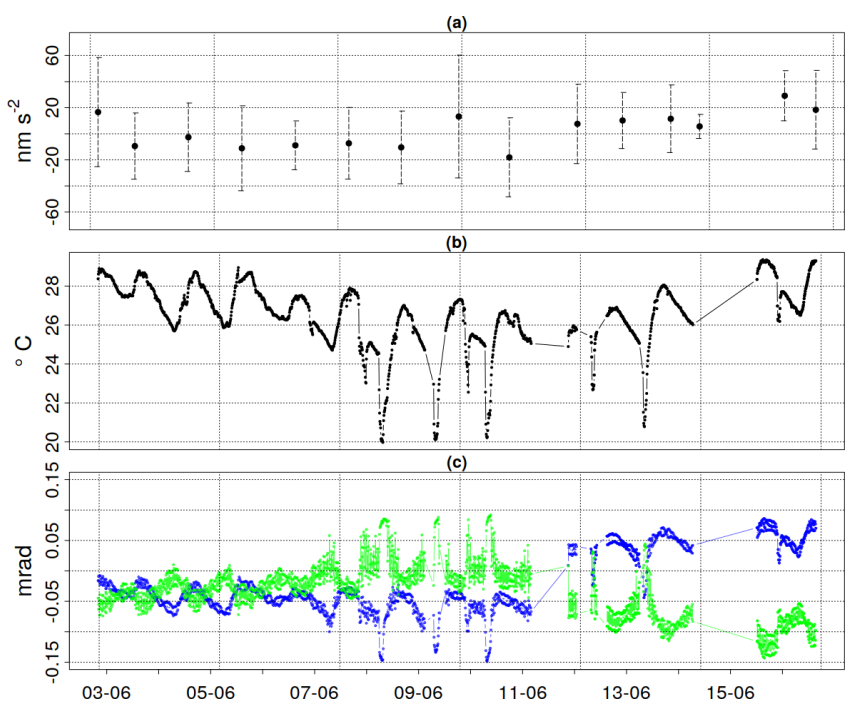

Figure 7. (a) AQG-B gravity residuals from the mean recorded during operation in a garage in Montpellier 2-17 June 2020. (b) External temperature in the garage recorded by AQG-B01 in degrees Celsius. (c) Sensor head tilts in $x$ (blue) and $y$ (green) given in mrad.

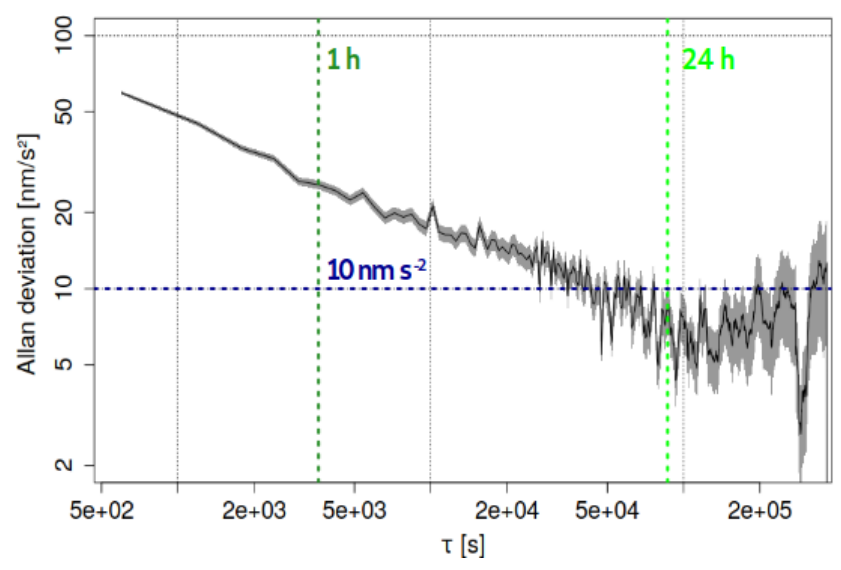

Figure 8. Allan deviation of 10 min AQG-B01 data obtained during operation in a garage in Montpellier. The horizontal blue dashed line shows the sensitivity benchmark of $10 \mathrm{~nm} \mathrm{~s}^{-2}$, the dark green vertical dashed line signifies the integration period of $1 \mathrm{~h}$, and the light green one that of $24 \mathrm{~h}$.

These results demonstrate the successful deployment of the AQG\#B01 in an urban environment. Stable measurements within $\pm 20 \mathrm{~nm} \mathrm{~s}^{-2}$ were achieved during 2 weeks of operation at elevated noise levels and in the presence of several environmental effects, in particular, temperature changes of several degrees Celsius within minutes and air movement when opening the garage doors.

\subsection{Coriolis effect}

To assess the potential impact of the Coriolis effect caused by changes in the sensor head's orientation we carried out mea- 


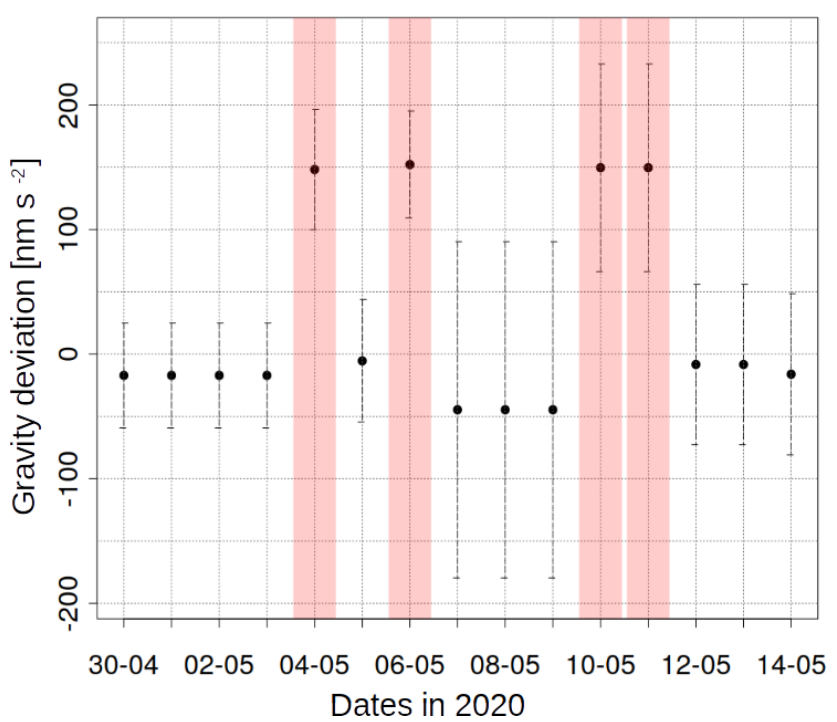

Figure 9. Residual gravity values in $\mathrm{nms}^{-2}$ obtained with the AQG-B01 during the Coriolis tests at Géosciences Montpellier in 2020: the red bars show a sensor head orientation of $180^{\circ}$ compared to the default set-up. Error bars refer to the standard deviation during $24 \mathrm{~h}$. The value of $g$ averaged over $24 \mathrm{~h}$ obtained on 10 June 2020 with the FG5-228 was subtracted. Horizontal grid lines show steps of $50 \mathrm{~nm} \mathrm{~s}^{-2}$.

surements rotated by $180^{\circ}$ with respect to the initial position. As can be seen in Fig. 9, the averaged gravity residuals for the two orientations show a $\delta g$ of approximately $150 \mathrm{~nm} \mathrm{~s}^{-2}$ relative to the FG5\#228 measurement. These results are much higher than expected, as it has not been observed in other AQG devices (Muquans, personal communication, 2020). These values are higher than the estimation of the Coriolis effect for the CAG (LNE-SYRTE), which yielded $4 \mathrm{~nm} \mathrm{~s}^{-2}$ uncertainty with peaks of up to $60 \mathrm{~nm} \mathrm{~s}^{-2}$ as a combination of several uncorrected effects (Louchet-Chauvet et al., 2011).

The sign of the Coriolis offset on the AQG\#B01 as compared to the absolute gravity measurement by the FG5\#228 has an important implication for the accuracy assessment and the interpretation of the differences between the two instruments: the FG5 measurement lies between the AQG\#B01 values for the two orientations during the tests in Montpellier. FG5\#228 measurements were higher than AQG\#B01 measurements in the Larzac observatory. The average difference between both instruments hence likely requires to be increased by $\sim 75 \mathrm{~nm} \mathrm{~s}^{-2}$, depending on the orientation of the AQG\#B01 sensor head.

Repeated and additional orientations (90 and $270^{\circ}$ ) are work in progress, as well as in comparison with other gravimeters. The authors are in contact with the developer for in-depth instrument tests. To date, the exact source of this change in $g$ has not been identified yet. It is thus recommended to pay attention to sensor head orientation during operation. It will be necessary in the future to evaluate through repeated tests if the impact of Coriolis is stable over time and whether a Coriolis correction can be established according to the orientation. The Coriolis effect needs to be included in the complete uncertainty budget.

\section{Conclusion and perspectives}

In this study, we show the results of instrumental tests aimed at the characterization of the AQG\#B01 for field applications. The AQG\#B01 prevailed as a reliable instrument in controlled laboratory conditions. Over 2 months no significant drift was observed and temporal variations are in coherence with the MGL-FG5. Its sensitivity after $24 \mathrm{~h}$ of data integration is close to that of the iGrav. In low-noise environments, the AQG\#B01 showed a sensitivity of $10 \mathrm{~nm} \mathrm{~s}^{-2}$ after $1 \mathrm{~h}$. On multi-year timescales the performance of the AQG in comparison with superconducting gravimeters still requires evidence with respect to noise and the resolution of sub-daily to weekly phenomena (Scherneck et al., 2020). AQG\#B01 $g$ residuals showed no correlation with manually increased tilts nor increased temperatures. An offset compared to the other gravimeters occurred and its causes are under investigation, as is the accuracy of the AQG\#B01. The AQG\#B01 time series obtained in the garage during 2 weeks of measurement was stable and did not show any significant correlation with temperature changes.

Furthermore, the obtained results suggest its suitability for field studies, upon further testing and validation. It is suitable for operation at least within a temperature range between 20 and $30^{\circ} \mathrm{C}$ over several days and weeks. Tilt correction is likely to be applied correctly even for relatively large tilts and during periods of higher temperatures.

For a thorough field evaluation, it is crucial to test larger temperature ranges. Operation in a garage where air circulation and humidity changes have not been controlled suggest that the measurement is not influenced by these factors. In future experiments, the potential influence of strong winds needs to be assessed. Due to the very recent delivery of the instrument, displacements between observatory locations and system mounting and un-mounting cycles have not been as frequent and need to be repeated. Further practical aspects such as the potential influence of cable insulation, unstable power supply, or tilts of the electronic and laser systems are to be assessed in due course.

The AQG\#B01 detected gravity changes caused by hydrology ranged over the same orders of magnitude as the iGrav. The resemblance between AQG\#B01 and iGrav\#002 residuals concerning their response to a rainfall event demonstrates the AQG\#B's capability to detect small transient mass changes. This speaks for the applications of the AQG\#B01 in hydrogeophysical studies among others. Mapping and quantification of water storage dynamics as an example for other transient mass changes could be one of many promising applications in this field. Jacob et al. (2010) mapped subsurface 
water storage heterogeneously distributed in the $100 \mathrm{~km}^{2}$ karst catchment in the Larzac using time-lapse micro-gravity. Gravity changes caused by local aquifer re- and discharge dynamics reached up to $220 \mathrm{~nm} \mathrm{~s}^{-2}$ with a survey precision between 24 and $50 \mathrm{~nm} \mathrm{~s}^{-2}$. Due to the strong and non-linear drift of relative gravimeters, the analysis of spatial surveys requires a least-squares network adjustment in which spatial and temporal gravity ties between stations within a survey network are considered (Jacob et al., 2010; Hector and Hinderer, 2016; Kennedy and Ferré, 2015). The 40 gravity stations were repeatedly visited with a relative spring gravimeter which required absolute FG5\#228 measurements as a reference for drift correction. Each of the four surveys yielded over 100 gravity ties as they covered all 40 stations in 12 loops consisting of 5 to 10 stations in each loop. Their study meant 7 full days of work for two operators for each survey due to numerous returns to the reference station. Meanwhile, Fores et al. (2016b) showed that relative gravimetry with a CG5 is highly sensitive to temperature. Correcting for temperature-induced effects shed new light on apparent spatial gravity differences measured in the field. It is possible that the spatial water storage heterogeneity suggested by Jacob et al. (2010) needs to be re-interpreted in view of remaining, uncorrected effects.

The applications in the studies mentioned show the potential gain in precision and time saved provided by the AQG. The AQG\#B01 allows us to combine two instruments in one. In the absence of a detectable drift, regular calibration is not required. In principle, no repeated loops would be necessary, as no gravity ties need to be established. The need for another indoor reference gravimeter becomes obsolete. High-precision gravity acquisition is possible with this new movable instrument. It is easy to set up and use without the need for operation and maintenance by an expert, as for the FG5. The survey time investment and data treatment could hence be reduced remarkably for spatial gravity mapping. The results so far suggest a sensitivity of between 10 and $20 \mathrm{~nm} \mathrm{~s}^{-2}$ after $1 \mathrm{~h}$. These first results are promising that the AQG\#B01 could reach significantly higher precision than relative gravimeters while being transportable. Even if the sensitivity of the AQG\#B01 during outdoor operation still needs to be investigated, the results suggest reliable operation in different temperatures, very likely reaching a higher sensitivity than that of relative gravimeters after only $1 \mathrm{~h}$ of measurement. The repeatability has been quantified as better than $50 \mathrm{~nm} \mathrm{~s}^{-2}$. Our study also revealed important precautions that need to be taken. The first results on the Coriolis effect suggest that for repeated studies the same orientation of the sensor head needs to be kept.

Its time-efficient deployment offers new possibilities for natural hazard monitoring and potential early-warning systems, some of which are already under investigation with the AQG\#A. Joint absolute and relative gravimetry monitoring of volcanic activity is studied at Mt Etna (Carbone et al., 2020). Another recent project focuses on the AQG on a mobile facility for a hydrological extreme event task force (Reich and Güntner, 2020). The observatory tests under controlled conditions aimed at singling out the effects of ambient conditions, mainly temperature. The next step is clearly to carry out tests outside the building. The estimation of the vertical gravity gradients by operating the AQG\#B01 on two different heights would add another application to the instrument's repertoire.

Data availability. The data are available at http://hplus.ore.fr/ en/cooke-et-al-2021-gimds-data (last access: 29 July 2020) and https://doi.org/10.5281/zenodo.4279110 (Cooke et al., 2020).

Author contributions. NLM carried out the instrumental tests. Data analysis was carried out by AKC. Planning of experiments and interpretation of results was a joint effort of CC, NLM, and AKC.

Competing interests. The study presented in this paper has been carried out in the context of the $\mathrm{PhD}$ thesis of Anne-Karin Cooke within the network ITN Enigma (https://enigma-itn.eu/esrn8-monitoring-water-storage-changes-new-portable-absolutequantum-gravimeter/, last access: 10 May 2020). The University of Montpellier (Géosciences) and the company Muquans, the developer of the new absolute quantum gravimeter, have a collaboration for this purpose. During a large part of her $\mathrm{PhD}$, Anne-Karin Cooke has been an employee of Muquans. Until October 2020 she was employed by the University of Montpellier.

Disclaimer. All measurement presented here are from the Larzac observatory hosted by OSU OREME (http://www.oreme.org, last access: 20 July 2020) and SNO H+ (http://hplus.ore.fr/, last access: 20 July 2020). Larzac observatory and instrumentation are mainly funded by the CNRS INSU, ANR, Montpellier University, OZCAR, RESIF, and Occitanie region. ENIGMA ITN has received funding from European Union's Horizon 2020 research and innovation programme under the Marie Sklodowska-Curie Grant Agreement No. 722028 .

Acknowledgements. We would like to thank Pierre Vermeulen and Laura Antoni-Micollier from Muquans for their active support, discussion, and feedback. Furthermore, we thank Sébastien Merlet for the discussion and advice. Last but not least, we acknowledge the inhabitants who allowed the experiments in the garage.

Financial support. This research has been supported by the European Commission, H2020 Research Infrastructures (ENIGMA (grant no. 722028)).

Review statement. This paper was edited by Ciro Apollonio and reviewed by Hans-Georg Scherneck and three anonymous referees. 


\section{References}

Allan, D.: Statistics of atomic frequency standards, Proc. IEEE, 54, 221-230, https://doi.org/10.1109/proc.1966.4634, 1966.

Bodart, Q., Merlet, S., Malossi, N., Santos, F. P. D., Bouyer, P., and Landragin, A.: A cold atom pyramidal gravimeter with a single laser beam, Appl. Phys. Lett., 96, 134101, https://doi.org/10.1063/1.3373917, 2010.

Bonvalot, S., Diament, M., and Gabalda, G.: Continuous gravity recording with Scintrex CG-3M meters: a promising tool for monitoring active zones, Geophys. J. Int., 135, 470-494, https://doi.org/10.1046/j.1365-246x.1998.00653.x, 1998.

Boy, J.-P. and Hinderer, J.: Study of the seasonal gravity signal in superconducting gravimeter data, J. Geodyn., 41, 227-233, https://doi.org/10.1016/j.jog.2005.08.035, 2006.

Boy, J. P. and Lyard, F.: High-frequency non-tidal ocean loading effects on surface gravity measurements, Geophys. J. Int., 175, 35-45, https://doi.org/10.1111/j.1365-246x.2008.03895.x, 2008.

Boy, J.-P., Longuevergne, L., Boudin, F., Jacob, T., Lyard, F., Llubes, M., Florsch, N., and Esnoult, M.-F.: Modelling atmospheric and induced non-tidal oceanic loading contributions to surface gravity and tilt measurements, J. Geodyn., 48, 182-188, https://doi.org/10.1016/j.jog.2009.09.022, 2009.

Camp, M. V. and Vauterin, P.: Tsoft: graphical and interactive software for the analysis of time series and Earth tides, Comput. Geosci., 31, 631-640, https://doi.org/10.1016/j.cageo.2004.11.015, 2005.

Camp, M. V., de Viron, O., Scherneck, H.-G., Hinzen, K.-G., Williams, S. D. P., Lecocq, T., Quinif, Y., and Camelbeeck, T.: Repeated absolute gravity measurements for monitoring slow intraplate vertical deformation in western Europe, J. Geophys. Res., 116, B08402, https://doi.org/10.1029/2010jb008174, 2011.

Carbone, D., Poland, M. P., Diament, M., and Greco, F.: The added value of time-variable microgravimetry to the understanding of how volcanoes work, Earth-Sci. Rev., 169, 146-179, https://doi.org/10.1016/j.earscirev.2017.04.014, 2017.

Carbone, D., Cannavò, F., Greco, F., Messina, A., Contrafatto, D., Siligato, G., Lautier-Gaud, J., Antoni-Micollier, L., Hammond, G., Middlemiss, R., Toland, K., de Zeeuw-van Dalfsen, E., Koymans, M., Rivalta, E., Nikkhoo, M., Bonadonna, C., and Frischknecht, C.: The NEWTON-g "gravity imager": a new window into processes involving subsurface fluids, EGU General Assembly 2020, Online, 4-8 May 2020, EGU2020-16329, https://doi.org/10.5194/egusphere-egu2020-16329, 2020

Cooke, A.-K., Champollion, C., and Le Moigne, N.: AQG\#B Data sets, Zenodo, https://doi.org/10.5281/zenodo.4279110, 2020.

Cooke, A.-K., Champollion, C., Janvier, C., Vermeulen, P., Le Moigne, N., and Merlet, S.: On the potential of vertical gravity gradients for soil moisture monitoring, J. Geodesy, submitted, 2021.

Creutzfeldt, B., Güntner, A., Klügel, T., and Wziontek, H.: Simulating the influence of water storage changes on the superconducting gravimeter of the Geodetic Observatory Wettzell, Germany, Geophysics, 73, WA95-WA104, https://doi.org/10.1190/1.2992508, 2008.

Creutzfeldt, B., Güntner, A., Thoss, H., Merz, B., and Wziontek, H.: Measuring the effect of local water storage changes on in situ gravity observations: Case study of the Geodetic Observatory Wettzell, Germany, Water Resour. Res., 46, W08531, https://doi.org/10.1029/2009wr008359, 2010.
Crossley, D., Hinderer, J., and Riccardi, U.: The measurement of surface gravity, Rep. Prog. Phys., 76, 046101, https://doi.org/10.1088/0034-4885/76/4/046101, 2013.

Deville, S., Jacob, T., Chéry, J., and Champollion, C.: On the impact of topography and building mask on time varying gravity due to local hydrology, Geophys. J. Int., 192, 82-93, https://doi.org/10.1093/gji/ggs007, 2012.

Ferguson, J. F., Chen, T., Brady, J., Aiken, C. L., and Seibert, J.: The 4D microgravity method for waterflood surveillance: Part II - Gravity measurements for the Prudhoe Bay reservoir, Alaska, Geophysics, 72, I33-I43, https://doi.org/10.1190/1.2435473, 2007.

Fores, B., Champollion, C., Moigne, N. L., Bayer, R., and Chéry, J.: Assessing the precision of the iGrav superconducting gravimeter for hydrological models and karstic hydrological process identification, Geophys. J. Int., 208, 269-280, https://doi.org/10.1093/gji/ggw396, 2016a.

Fores, B., Champollion, C., Moigne, N. L., and Chery, J.: Impact of ambient temperature on spring-based relative gravimeter measurements, J. Geod., 91, 269-277, https://doi.org/10.1007/s00190-016-0961-2, 2016b.

Fores, B., Champollion, C., Mainsant, G., Albaric, J., and Fort, A.: Monitoring Saturation Changes with Ambient Seismic Noise and Gravimetry in a Karst Environment, Vadose Zone J., 17, 170 163, https://doi.org/10.2136/vzj2017.09.0163, 2018.

Fores, B., Klein, G., Moigne, N. L., and Francis, O.: LongTerm Stability of Tilt-Controlled gPhoneX Gravimeters, J. Geophys. Res.-Sol. Ea., 124, 12264-12276, https://doi.org/10.1029/2019jb018276, 2019.

Francis, O., Baumann, H., Volarik, T., Rothleitner, C., Klein, G., Seil, M., Dando, N., Tracey, R., Ullrich, C., Castelein, S., Hua, H., Kang, W., Chongyang, S., Songbo, X., Hongbo, T., Zhengyuan, L., Pálinkás, V., Kostelecký, J., Mäkinen, J., Näränen, J., Merlet, S., Farah, T., Guerlin, C., Santos, F. P. D., Moigne, N. L., Champollion, C., Deville, S., Timmen, L., Falk, R., Wilmes, H., Iacovone, D., Baccaro, F., Germak, A., Biolcati, E., Krynski, J., Sekowski, M., Olszak, T., Pachuta, A., Agren, J., Engfeldt, A., Reudink, R., Inacio, P., McLaughlin, D., Shannon, G., Eckl, M., Wilkins, T., van Westrum, D., and Billson, R.: The European Comparison of Absolute Gravimeters 2011 (ECAG2011) in Walferdange, Luxembourg: results and recommendations, Metrologia, 50, 257-268, https://doi.org/10.1088/00261394/50/3/257, 2013.

Freier, C., Hauth, M., Schkolnik, V., Leykauf, B., Schilling, M., Wziontek, H., Scherneck, H.-G., Müller, J., and Peters, A.: Mobile quantum gravity sensor with unprecedented stability, J. Phys. Conf. Ser., 723, 012050, https://doi.org/10.1088/17426596/723/1/012050, 2016.

Gaillardet, J., Braud, I., Hankard, F., Anquetin, S., Bour, O., Dorfliger, N., de Dreuzy, J., Galle, S., Galy, C., Gogo, S., Gourcy, L., Habets, F., Laggoun, F., Longuevergne, L., Borgne, T. L., Naaim-Bouvet, F., Nord, G., Simonneaux, V., Six, D., Tallec, T., Valentin, C., Abril, G., Allemand, P., Arènes, A., Arfib, B., Arnaud, L., Arnaud, N., Arnaud, P., Audry, S., Comte, V. B., Batiot, C., Battais, A., Bellot, H., Bernard, E., Bertrand, C., Bessière, H., Binet, S., Bodin, J., Bodin, X., Boithias, L., Bouchez, J., Boudevillain, B., Moussa, I. B., Branger, F., Braun, J. J., Brunet, P., Caceres, B., Calmels, D., Cappelaere, B., Celle-Jeanton, H., Chabaux, F., Chalikakis, K., Champollion, C., Copard, Y., Co- 
tel, C., Davy, P., Deline, P., Delrieu, G., Demarty, J., Dessert, C., Dumont, M., Emblanch, C., Ezzahar, J., Estèves, M., Favier, V., Faucheux, M., Filizola, N., Flammarion, P., Floury, P., Fovet, O., Fournier, M., Francez, A. J., Gandois, L., Gascuel, C., Gayer, E., Genthon, C., Gérard, M. F., Gilbert, D., Gouttevin, I., Grippa, M., Gruau, G., Jardani, A., Jeanneau, L., Join, J. L., Jourde, H., Karbou, F., Labat, D., Lagadeuc, Y., Lajeunesse, E., Lastennet, R., Lavado, W., Lawin, E., Lebel, T., Bouteiller, C. L., Legout, C., Lejeune, Y., Meur, E. L., Moigne, N. L., Lions, J., Lucas, A., Malet, J. P., Marais-Sicre, C., Maréchal, J. C., Marlin, C., Martin, P., Martins, J., Martinez, J. M., Massei, N., Mauclerc, A., Mazzilli, N., Molénat, J., Moreira-Turcq, P., Mougin, E., Morin, S., Ngoupayou, J. N., Panthou, G., Peugeot, C., Picard, G., Pierret, M. C., Porel, G., Probst, A., Probst, J. L., Rabatel, A., Raclot, D., Ravanel, L., Rejiba, F., René, P., Ribolzi, O., Riotte, J., Rivière, A., Robain, H., Ruiz, L., SanchezPerez, J. M., Santini, W., Sauvage, S., Schoeneich, P., Seidel, J. L., Sekhar, M., Sengtaheuanghoung, O., Silvera, N., Steinmann, M., Soruco, A., Tallec, G., Thibert, E., Lao, D. V., Vincent, C., Viville, D., Wagnon, P., and Zitouna, R.: OZCAR: The French Network of Critical Zone Observatories, Vadose Zone J., 17, 180067, https://doi.org/10.2136/vzj2018.04.0067, 2018.

Geiger, R., Landragin, A., Merlet, S., and Santos, F. P. D.: Highaccuracy inertial measurements with cold-atom sensors, AVS Quantum Sci., 2, 024702, https://doi.org/10.1116/5.0009093, 2020.

Gillot, P., Francis, O., Landragin, A., Santos, F. P. D., and Merlet, S.: Stability comparison of two absolute gravimeters: optical versus atomic interferometers, Metrologia, 51, L15-L17, https://doi.org/10.1088/0026-1394/51/5/115, 2014.

Güntner, A., Reich, M., Mikolaj, M., Creutzfeldt, B., Schroeder, S., and Wziontek, H.: Landscape-scale water balance monitoring with an iGrav superconducting gravimeter in a field enclosure, Hydrol. Earth Syst. Sci., 21, 3167-3182, https://doi.org/10.5194/hess-21-3167-2017, 2017.

Hauth, M., Freier, C., Schkolnik, V., Senger, A., Schmidt, M., and Peters, A.: First gravity measurements using the mobile atom interferometer GAIN, Appl. Phys. B, 113, 49-55, https://doi.org/10.1007/s00340-013-5413-6, 2013.

Hector, B. and Hinderer, J.: pyGrav, a Python-based program for handling and processing relative gravity data, Comput. Geosci., 91, 90-97, https://doi.org/10.1016/j.cageo.2016.03.010, 2016.

Hector, B., Hinderer, J., Séguis, L., Boy, J.-P., Calvo, M., Descloitres, M., Rosat, S., Galle, S., and Riccardi, U.: Hydrogravimetry in West-Africa: First results from the Djougou (Benin) superconducting gravimeter, J. Geodyn., 80, 34-49, https://doi.org/10.1016/j.jog.2014.04.003, 2014.

Hector, B., Séguis, L., Hinderer, J., Cohard, J.-M., Wubda, M., Descloitres, M., Benarrosh, N., and Boy, J.-P.: Water storage changes as a marker for base flow generation processes in a tropical humid basement catchment (Benin): Insights from hybrid gravimetry, Water Resour. Res., 51, 8331-8361, https://doi.org/10.1002/2014wr015773, 2015.

Hinderer, J., Crossley, D., and Warburton, R.: Superconducting Gravimetry, in: Treatise on Geophysics, 59-115, Elsevier, Oxford, UK, https://doi.org/10.1016/b978-0-444-53802-4.00062-2, 2015 .
Hinze, W. J., Von Frese, R. R., and Saad, A. H.: Gravity and magnetic exploration: Principles, practices, and applications, Cambridge University Press, New York, 2013.

Huang, P.-W., Tang, B., Chen, X., Zhong, J.-Q., Xiong, Z.-Y., Zhou, L., Wang, J., and Zhan, M.-S.: Accuracy and stability evaluation of the $85 \mathrm{Rb}$ atom gravimeter WAG-H5-1 at the 2017 International Comparison of Absolute Gravimeters, Metrologia, 56, 045012, https://doi.org/10.1088/1681-7575/ab2f01, 2019.

Hwang, C., Cheng, T.-C., Cheng, C., and Hung, W.: Land subsidence using absolute and relative gravimetry: a case study in central Taiwan, Surv. Rev., 42, 27-39, https://doi.org/10.1179/003962609x451672, 2010.

Imanishi, Y.: A Network of Superconducting Gravimeters Detects Submicrogal Coseismic Gravity Changes, Science, 306, 476478, https://doi.org/10.1126/science.1101875, 2004.

Jacob, T., Bayer, R., Chery, J., Jourde, H., Moigne, N. L., Boy, J.-P., Hinderer, J., Luck, B., and Brunet, P.: Absolute gravity monitoring of water storage variation in a karst aquifer on the larzac plateau (Southern France), J. Hydrol., 359, 105-117, https://doi.org/10.1016/j.jhydrol.2008.06.020, 2008.

Jacob, T., Bayer, R., Chery, J., and Moigne, N. L.: Timelapse microgravity surveys reveal water storage heterogeneity of a karst aquifer, J. Geophys. Res., 115, B06402, https://doi.org/10.1029/2009jb006616, 2010.

Jiang, Z., Pálinkáš, V., Arias, F. E., Liard, J., Merlet, S., Wilmes, H., Vitushkin, L., Robertsson, L., Tisserand, L., Santos, F. P. D., Bodart, Q., Falk, R., Baumann, H., Mizushima, S., Mäkinen, J., Bilker-Koivula, M., Lee, C., Choi, I. M., Karaboce, B., Ji, W., Wu, Q., Ruess, D., Ullrich, C., Kostelecký, J., Schmerge, D., Eckl, M., Timmen, L., Moigne, N. L., Bayer, R., Olszak, T., Ågren, J., Negro, C. D., Greco, F., Diament, M., Deroussi, S., Bonvalot, S., Krynski, J., Sekowski, M., Hu, H., Wang, L. J., Svitlov, S., Germak, A., Francis, O., Becker, M., Inglis, D., and Robinson, I.: The 8th International Comparison of Absolute Gravimeters 2009: the first Key Comparison (CCM.G-K1) in the field of absolute gravimetry, Metrologia, 49, 666-684, https://doi.org/10.1088/0026-1394/49/6/666, 2012.

Kennedy, J., Ferré, T. P. A., and Creutzfeldt, B.: Time-lapse gravity data for monitoring and modeling artificial recharge through a thick unsaturated zone, Water Resour. Res., 52, 7244-7261, https://doi.org/10.1002/2016wr018770, 2016.

Kennedy, J. R. and Ferré, T. P.: Accounting for time- and spacevarying changes in the gravity field to improve the network adjustment of relative-gravity data, Geophys. J. Int., 204, 892-906, https://doi.org/10.1093/gji/ggv493, 2015.

Louchet-Chauvet, A., Farah, T., Bodart, Q., Clairon, A., Landragin, A., Merlet, S., and Santos, F. P. D.: The influence of transverse motion within an atomic gravimeter, New J. Phys., 13, 065025, https://doi.org/10.1088/1367-2630/13/6/065025, 2011.

Mazzotti, S., Lambert, A., Henton, J., James, T. S., and Courtier, N.: Absolute gravity calibration of GPS velocities and glacial isostatic adjustment in mid-continent North America, Geophys. Res. Lett., 38, L24311, https://doi.org/10.1029/2011g1049846, 2011.

Ménoret, V., Vermeulen, P., Moigne, N. L., Bonvalot, S., Bouyer, P., Landragin, A., and Desruelle, B.: Gravity measurements below 10-9 g with a transportable absolute quantum gravimeter, Sci. Rep., 8, 12300, https://doi.org/10.1038/s41598-018-30608$1,2018$. 
Merlet, S., Bodart, Q., Malossi, N., Landragin, A., Santos, F. P. D., Gitlein, O., and Timmen, L.: Comparison between two mobile absolute gravimeters: optical versus atomic interferometers, Metrologia, 47, L9-L11, https://doi.org/10.1088/00261394/47/4/101, 2010.

Mollenhauer, H., Kasner, M., Haase, P., Peterseil, J., Wohner, C., Frenzel, M., Mirtl, M., Schima, R., Bumberger, J., and Zacharias, S.: Long-term environmental monitoring infrastructures in Europe: observations, measurements, scales, and socioecological representativeness, Sci. Total Environ., 624, 968-978, https://doi.org/10.1016/j.scitotenv.2017.12.095, 2018.

Niebauer, T. M.: Gravimetric methods - absolute gravimeter?: instruments concepts and implementation, in: Treatise on Geophysics, vol. 3, edited by: Schubert, G., Elsevier, Oxford, UK, 37-57, 2015

Niebauer, T. M., Sasagawa, G. S., Faller, J. E., Hilt, R., and Klopping, F.: A new generation of absolute gravimeters, Metrologia, 32, 159-180, https://doi.org/10.1088/0026-1394/32/3/004, 1995.

Olsson, P.-A., Breili, K., Ophaug, V., Steffen, H., Bilker-Koivula, M., Nielsen, E., Oja, T., and Timmen, L.: Postglacial gravity change in Fennoscandia - three decades of repeated absolute gravity observations, Geophys. J. Int., 217, 1141-1156, https://doi.org/10.1093/gji/ggz054, 2019.

Pearson-Grant, S., Franz, P., and Clearwater, J.: Gravity measurements as a calibration tool for geothermal reservoir modelling, Geothermics, 73, 146-157, https://doi.org/10.1016/j.geothermics.2017.06.006, 2018.

Peters, A., Chung, K. Y., and Chu, S.: High-precision gravity measurements using atom interferometry, Metrologia, 38, 25-61, https://doi.org/10.1088/0026-1394/38/1/4, 2001.

Reich, M. and Güntner, A.: A concept of hybrid terrestrial gravimetry and cosmic ray neutron sensing for investigating hydrological extreme events, EGU General Assembly 2020, Online, 4-8 May 2020, EGU2020-13624, https://doi.org/10.5194/egusphereegu2020-13624, 2020.

Reich, M., Mikolaj, M., Blume, T., and Güntner, A.: Reducing gravity data for the influence of water storage variations beneath observatory buildings, Geophysics, 84, EN15-EN31, https://doi.org/10.1190/geo2018-0301.1, 2019.

Rodell, M., Houser, P. R., Jambor, U., Gottschalck, J., Mitchell, K., Meng, C.-J., Arsenault, K., Cosgrove, B., Radakovich, J., Bosilovich, M., Entin, J. K., Walker, J. P., Lohmann, D., and Toll, D.: The Global Land Data Assimilation System, B. Am. Meteorol. Soc., 85, 381-394, https://doi.org/10.1175/bams-85-3-381, 2004.
Scherneck, H.-G., Rajner, M., and Engfeldt, A.: Superconducting gravimeter and seismometer shedding light on FG5's offsets, trends and noise: what observations at Onsala Space Observatory can tell us, J. Geod., 94, 80, https://doi.org/10.1007/s00190-02001409-0, 2020.

Sugihara, M., Nishi, Y., Ikeda, H., Nawa, K., and Ishido, T.: Monitoring $\mathrm{CO}_{2}$ Injection at the Tomakomai Field Using Highsensitivity Continuous Gravimetry, Energy Procedia, 114, 40204027, https://doi.org/10.1016/j.egypro.2017.03.1542, 2017.

Van Camp, M., de Viron, O., Pajot-Métivier, G., Casenave, F., Watlet, A., Dassargues, A., and Vanclooster, M.: Direct measurement of evapotranspiration from a forest using a superconducting gravimeter, Geophys. Res. Lett., 43, 10-225, https://doi.org/10.1002/2016GL070534, 2016.

Van Camp, M., de Viron, O., Watlet, A., Meurers, B., Francis, O., and Caudron, C.: Geophysics From Terrestrial TimeVariable Gravity Measurements, Rev. Geophys., 55, 938-992, https://doi.org/10.1002/2017rg000566, 2017.

Volcke, P., Pequegnat, C., Brichet-Billet, B., Lecointre, A., Wolyniec, D., and Guéguen, P.: RESIF national datacentre: new features and upcoming evolutions, Geophys. Res. Abstr., EGU2014-12270, EGU General Assembly 2014, Vienna, Austria, 2014.

Wenzel, H.-G.: The nanogal software: Earth tide data processing package ETERNA 3.30, Bull. Inf. Marées Terrestres, 124, 94259439, 1996.

Wu, S., Fend, J., Li, C., Su, D., Wand, Q., Hu, R., Hu, L., Xu, J., Ji, W., Ullrich, C., Pálinkáš, V., Kostelecký, J., Bilker-Koivula, M., Näränen, J., Merlet, S., Moigne, N. L., Mizushima, S., Francis, O., Choi, I.-M., Kim, M.-S., Alotaibi, H. M., Aljuwayr, A., Baumann, H., Priruenrom, T., Woradet, N., KIRBAŞ, C., Coşkun, I., and Newel, D.: The results of CCM.G-K2.2017 key comparison, Metrologia, 57, 07002, https://doi.org/10.1088/00261394/57/1a/07002, 2020. 